\title{
Book Review: Pedometrics: How Relevant Is It to the Research on Soil Processes?
}

\author{
Philippe C. Baveye* \\ UMR ECOSYS, AgroParisTech, Université Paris-Saclay, Thiverval-Grignon, France
}

Keywords: geostatistics, spatial variability, soil science, geomatic methods, soil processes

\section{A Book Review on \\ Pedometrics}

Alex B. McBratney, Budiman Minasny, Uta Stockmann, (Cham: Springer International Publishing AG), 2018, 720 pages, \$240 (hardcover), \$182 (e-book), ISBN: 978-3-319-63437-1, and cover page given in Figure 1.

OPEN ACCESS

Edited by:

Luiz Fernando Wurdig Roesch,

Federal University of Pampa, Brazil

Reviewed by:

Christina Bogner,

University of Cologne, Germany

Ana Teresa Lima,

Federal University of Espirito Santo,

Brazil

*Correspondence:

Philippe C. Baveye

Philippe.Baveye@AgroParisTech.fr

Specialty section:

This article was submitted to

Soil Processes,

a section of the journal

Frontiers in Environmental Science

Received: 01 February 2019

Accepted: 19 March 2019

Published: 09 April 2019

Citation:

Baveye PC (2019) Book Review:

Pedometrics: How Relevant Is it to the

Research on Soil Processes?

Front. Environ. Sci. 7:44.

doi: 10.3389/fenvs.2019.00044
Over the last three decades, hundreds of articles, quite a few books, and several international meetings (e.g., Vanwalleghem et al., 2018) have been devoted to the field of "pedometrics." The aims that are pursued in this field, and the achievements accomplished to date, may not be familiar to researchers working on the description of physical, (bio)chemical, or microbiological processes in soils. The recent publication by Springer of a comprehensive treatise on the topic affords an opportunity to gain some understanding of what the field is about, and, perhaps of more direct interest to readers of our section of the journal, to assess to what extent the content of the book is relevant to the research on soil processes.

The field covered by the term "pedometrics", used analogously to other words such as biometrics, psychometrics, or econometrics (Webster, 1994), has evolved over the years, from "the use of quantitative methods for the study of soil distribution and genesis and as a sustainable resource" when the neologism was first coined in 1986, to "the development and application of statistical and mathematical methods applicable to data analysis problems in soil science" in the book reviewed here. An additional meaning, due to Webster (1994) is "soil science under uncertainty," implying that pedometrics deals with uncertainty in soil models that is due to deterministic or stochastic variation, vagueness, and lack of knowledge of soil properties and processes. Thus, from the narrow focus of pedometrics in 1986 on quantitative aspects of soil distribution, there has been an intent, at least, to broaden the scope to include pretty much any application of statistics and mathematics to soil science. Indeed, according to this broader intent, any quantitative research on soils could in principle fall within the purview of pedometrics. With this understanding, one might assume a priori that the field could be of direct relevance to the research on soil processes. However, this warrants further scrutiny.

The Pedometrics book comprises 23 chapters, written by 44 different authors and organized according to 7 parts: Introduction: What is pedometrics? (Part I, 1 chapter, 45 pages), Statistical footings (Part II, 3 chapters, 71 pages), Soil measurements and properties (Part III, 3 chapters, 107 pages), Soil materials, horizons and profiles (Part IV, 2 chapters, 67 pages), Soil variation in space and time (Part V, 3 chapters, 71 pages), Soil genesis (Part VI, 2 chapters, 47 pages), and Application of pedometrics (Part VII, 4 chapters, 123 pages). Judging from the dates of the references cited and in particular the fact that only 3 chapters contain any reference to work published in 2017, most of the contributed texts appear to have been completed in 2016, a relatively long time before the publication of the book, and therefore do not present the most up-to-date material in some areas. 
Chapter 22, on broad-scale soil monitoring schemes, is even a reprinted version of a Pedosphere article published in 2012. To some extent, it is unavoidable for edited books, which can be published only when all contributions are in, to have chapters with a range of completion dates. One could probably argue that virtual special issues of electronic journals (like the "Research Topics" at Frontiers), in which articles are published as soon as they are accepted, and from which e-books can emanate if there is a demand for them, constitute more efficient venues to disseminate up-to-date information in a timely manner. As an additional advantage, journal articles are perhaps reviewed more carefully than is the case with book chapters, and in particular more attention tends to be placed on whether or not they provide an appropriate coverage of previous work.

A word count analysis of the book, using the search feature associated with the e-book version, provides a fittingly quantitative perspective on its content. Words like "variogram," "geostatistic," "variability," "mapping," or "model" are found with great frequency in the text and cited references, respectively 539, 232, 259, and 319, 1552 times. Words like "normality" or "nonparametric," which provide a counterpoint to the traditional Gaussian foundation of geostatistics, are seldom mentioned, respectively 12 and 16 times, even though practical experience with non-normally distributed soil data suggests that they should be paid significantly more attention. Terms that relate to topical areas in the spatial analysis of soils, such as "Bayesian" (21) or "machine learning" (25), make few appearances, which is surprising, in view of the enthusiasm with which researchers have adopted the associated perspectives in recent years (e.g., Douaik et al., 2004; Chammartin et al., 2013; Keskin et al., 2019; Sergeev et al., 2019). Insofar as words typically used in the description of specific soil processes are concerned, very rare to virtually inexistent in the book are mentions of "tomography" (19 occurrences), "leaching" (17), "macropore" (18), "bacteria (7)", “fungal” (4), "preferential” (3), "swelling” (1), "earthworm” (1), or "macrofauna" $(0)$.

In many ways, these occurrence statistics convey the strong impression, confirmed upon reading through the text, that the book, and by extension, the field of pedometrics, are still predominantly focused on a very classical presentation of geostatistics and of its application to the description of spatially varying, largely static, characteristics of soils, with the specific objective of producing maps. Pedostransfer functions are advocated as a way to translate the information contained in or associated with these maps into parameters that may be useful to describe other soil features, and several applications presented in the book illustrate their use. Nevertheless, the bulk of the text is a description of parametric geostatistical methods available to manipulate spatial data related to soils, in line largely with the 1986 definition of pedometrics mentioned earlier. In that context, the level of the text is that of a treatise, meant mostly for specialists, and may not be ideally suited for researchers with little background knowledge, who might want to learn not just about geostatistics, but more broadly about the quantitative analysis of spatial and spatio-temporal data. From that standpoint, books like those of Bivand et al. (2013), Chun and Griffith (2013), or Cressie (2015), might be more suitable introductions to the field.

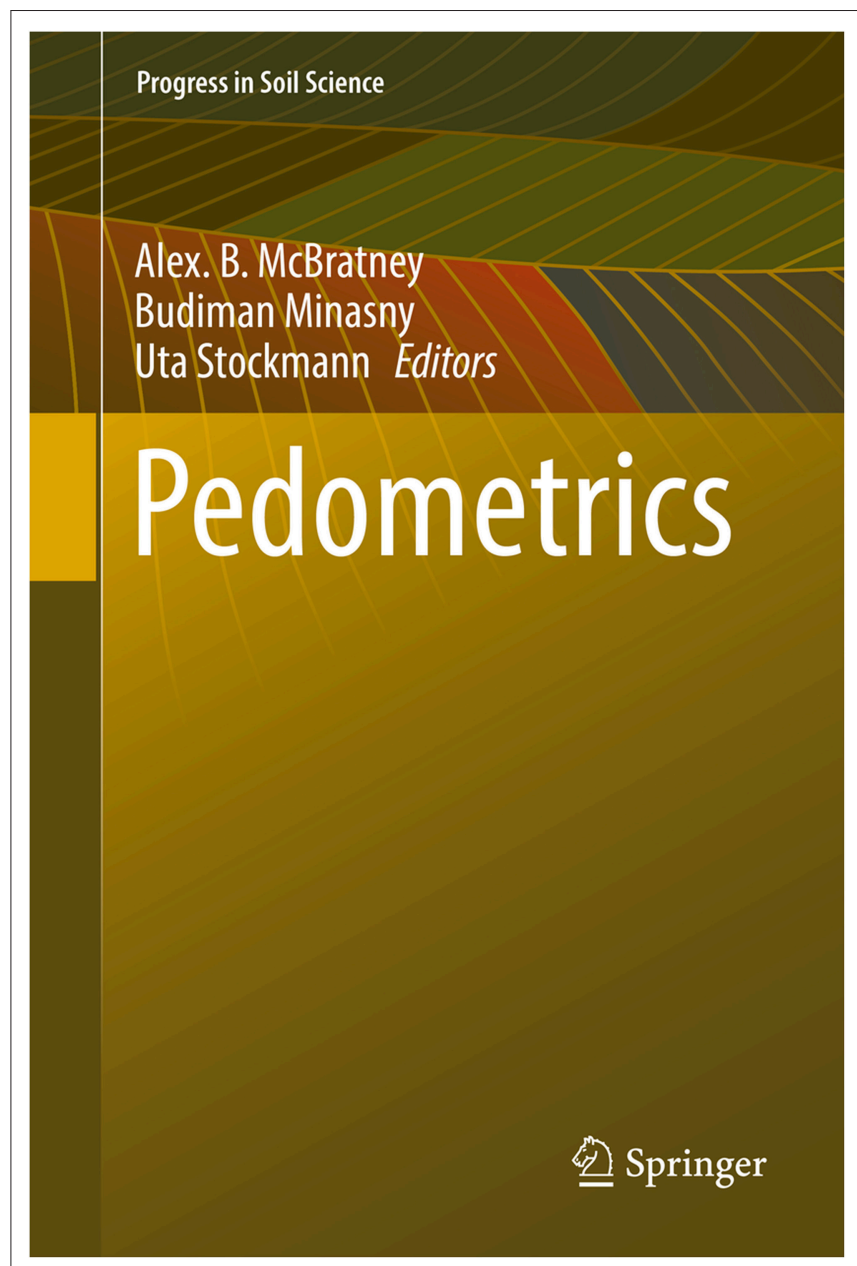

FIGURE 1 | Book cover of Pedometrics (Copyright @ 2018 Springer International Publishing AG, Cham, Switzerland. Reprinted with permission).

Anyone who is keen to transition to the Bayesian perspective, or is interested in the analysis of spatio-temporal data, both of which in my view are steps in the right direction, may want to turn to books written by Cressie and Wikle (2011) or Blangiardo and Cameletti (2015).

From a process-oriented viewpoint, an aspect of the Pedometrics book that is likely to surprise readers is the fact that, aside from the production of maps and more recently of digital maps, little is said in the book about possible purposes pursued by pedometrics, as if the development of geostatistical methods and their application to mapping were, in and of themselves, satisfactory objectives. One could make in this context the same comments that were made decades ago by, e.g., De Bakker (1970) or Schelling (1970) with respect to soil classification. De Bakker (1970), in particular, wrote that "from an extensive survey of recent literature it appears that much is said about principles of soil classification, whereas there is often a lack of definite statements about purposes. As the character of any system of soil classification is partly defined by the ultimate purposes which the drafters had in mind, it is very important to know these 
purposes." Indeed, a soil map made for fishermen, with only two classes (soils with- and soils without earthworms), would in all likelihood not be very useful for a wide range of other applications. In a rational approach to the spatial (and temporal) heterogeneity of soils, and to avoid putting the cart before the horse, it would seem that the first step should be to state clearly what question needs to be addressed and at what scale. From there should follow the gathering of appropriate data and the selection of the method(s) to be used for their analysis. One could argue that this crucial issue of the ultimate purposes of data gathering and analysis has not been sufficiently discussed so far in the soil science literature, even in the latest massive effort to produce a global digital map, in spite of vivid illustration that purpose matters (e.g., Basu et al., 2010; Baveye and Laba, 2015). In this respect, by avoiding to bring up the issue, the Pedometrics book regrettably adheres to a long tradition ${ }^{1}$.

Nevertheless, several of the chapters may in principle be of interest to researchers working on soil processes. Chapters 18 and 19 in Part VI deal with the genesis of soils, and involve many "pedogenetic" processes whose study over the years have produced a number of mathematical models, with which researchers in any discipline of soil science should probably be acquainted. Chapter 18, on mysterious-sounding, so-called "Clorpt" functions (standing for "climate, organisms, topography, parent material, and time"), is very short. Chapter 19 is significantly longer and covers some of the relevant literature, but not all of it. In particular, the text ignores all the very interesting research carried out in the last decade on the short-term evolution of soils, e.g., in response to anthropic effects (Cornu et al., 2009, 2012a,b; Montagne and Cornu, 2010; Montagne et al., 2013, 2016; Keyvanshokouhi et al., 2016; van Oort et al., 2017; Bakker et al., 2018).

\footnotetext{
${ }^{1}$ To start this much-needed discussion on the right footage, perhaps soil science students should be encouraged to read the mystery novel "Murder on the links" published in 1923 by Agatha Christie. In it, the author contrasts two investigative approaches. Giraud, a detective of the Paris Sûreté, devotes a lot of time and energy gathering clues of all sorts. He is repeatedly unnerved by Hercule Poirot, who on the contrary sits comfortably in an armchair, contemplating various theories, and seldom goes outside to find clues. The philosophy of Monsieur Poirot is that, unless one has a theory, one cannot tell which clues are relevant, and it is a waste of time to collect them. Needless to say, the Belgian detective solves the case in the end....
}

\section{REFERENCES}

Bakker, E., Hubert, F., Wander, M. M., and Lanson, B. (2018). Soil development under continuous agriculture at the Morrow plots experimental fields from X-ray diffraction profile modelling. Soil Syst. 2:46. doi: 10.3390/soilsystems 2030046

Basu, N. B., Rao, P. S. C., Winzeler, H. E., Kumar, S., Owens, P., and Merwade, V. (2010). Parsimonious modeling of hydrologic responses in engineered watersheds: structural heterogeneity versus functional homogeneity. Water Resour. Res. 46:W04501. doi: 10.1029/2009 WR007803

Baveye, P. C., Otten, W., Kravchenko, A., Balseiro Romero, M., Beckers, É., Chalhoub, M., et al. (2018). Emergent properties of microbial activity in heterogeneous soil microenvironments: different research approaches are slowly converging, yet major challenges remain. Front. Microbiol. 8:1364. doi: $10.3389 /$ fmicb. 2017.01364
Two other chapters are particularly relevant to the research on soil processes. Chapter 6 (Tarquis et al., 2018) deals with the scaling characteristics of soil structure, and presents in detail some of the measurement techniques (e.g., Xray computed tomography) and mathematical tools (fractal geometry, multifractal measures, Minkowski functionals) that have been used in the past two decades to characterize the geometry and connectivity of the pore space in soils, as well as the architecture (formerly referred to as the "structure") of the solid phase. These different topics, as well as the upscaling of soil characteristics to the macroscopic scale, remain extremely challenging at the moment (e.g., Baveye et al., 2018), and researchers who are confronted with them in the study of a wide range of soil processes will find this chapter an especially valuable source of information. Another chapter, Chapter 17 (Rossiter et al., 2018) also presents material that readers of this section of our journal are likely to find particularly interesting. The chapter provides a very good coverage of the literature dealing with the valuation of the various ecosystem services delivered by soils to human populations. The literature has expanded greatly in this very topical area since mid-2016, when this chapter was completed, but nevertheless the very lucid discussion by Rossiter et al. (2018) of the limitations of the economic valuation and of its use for decision making, even when envisaged in an ecological economics context, is well worth reading.

Given the prohibitively high cost of this book, even at discount book sellers, it is unlikely that many soil scientists, especially if they are interested predominantly in the dynamics of soil processes, will have much incentive in purchasing a copy of it for their own library. The table of contents of the book can be consulted on the Springer web site, or on the site of Google books (where a preview of some of the pages is also available). From there on, the best option may be to do what we used to do with journal articles in the "good old days", i.e., ask the authors of chapters of interest for a (now electronic) reprint of their work.

\section{AUTHOR CONTRIBUTIONS}

The author confirms being the sole contributor of this work and has approved it for publication.
Baveye, P. S. C., and Laba, M. (2015). Moving away from the geostatistical lamppost: why, where, and how does the spatial heterogeneity of soils matter? Ecol. Model. 298, 24-38. doi: 10.1016/j.ecolmodel.2014.03.018

Bivand, R. S., Pebesma, E., and Gómez-Rubio, V. (2013). Applied Spatial Data Analysis with R, 2nd Edn. New York, NY: Springer.

Blangiardo, M., and Cameletti, M. (2015). Spatial and Spatio-Temporal Bayesian Models with $R$ - INLA. New York, NY: John Wiley and Sons, Inc.

Chammartin, F., Scholte, R. G. C., Guimarães, L. H., Tanner, M., Utzinger, J., and Vounatsou, P. (2013). Soil-transmitted helminth infection in South America: a systematic review and geostatistical meta-analysis. Lancet Infect. Dis. 13, 507-518. doi: 10.1016/S1473-3099(13)70071-9

Chun, Y., and Griffith, D. A. (2013). Spatial Statistics and Geostatistics: Theory and Applications for Geographic Information Science and Technology. New York, NY: Sage Publications.

Cornu, S., Montagne, D., Daroussin, J., and Cousin, I. (2012a). Imageanalytically derived conceptual model of Albeluvisol morphological 
degradation induced by artificial drainage in France. Geoderma 189, 296-303. doi: 10.1016/j.geoderma.2012.05.024

Cornu, S., Montagne, D., Hubert, F., Barre, P., and Caner, L. (2012b). Evidence of short-term clay evolution in soils under human impact. Compt. Rendus Geosci. 344, 747-757. doi: 10.1016/j.crte.2012.09.005

Cornu, S., Montagne, D., and Vasconcelos, P. M. (2009). Dating constituent formation in soils to determine rates of soil processes: a review. Geoderma 153, 293-303. doi: 10.1016/j.geoderma.2009.08.006

Cressie, N. (2015). Statistics for Spatial Data (Revised edition). New York, NY: Wiley Classics Library; Wiley-Interscience.

Cressie, N., and Wikle, C. K. (2011). Statistics for Spatio-Temporal Data. New York, NY: John Wiley and Sons, Inc.

De Bakker, H. (1970). Purposes of soil classification. Geoderma 4, 195-208. doi: 10.1016/0016-7061(70)90003-0

Douaik, A., van Meirvenne, M., Tóth, T., and Serre, M. (2004). Space-time mapping of soil salinity using probabilistic bayesian maximum entropy. Sotchast. Environ. Res. Risk Assess. 18, 219-227. doi: 10.1007/s00477-004-0177-5

Keskin, H., Grunwald, S., and Harris, W. G. (2019). Digital mappng of soil carbon fractions with machine learning. Geoderma 339, 40-58. doi: 10.1016/j.geoderma.2018.12.037

Keyvanshokouhi, S., Cornu, S., Samouelian, A., and Finke, P. (2016). Evaluating SoilGen 2 as a tool for projecting soil evolution induced by global change. Sci. Tot. Environ. 571, 110-123. doi: 10.1016/j.scitotenv.2016.07.119

Montagne, D., and Cornu, S. (2010). Do we need to include soil evolution module in models for prediction of future climate change? Clim. Change 98, 75-86. doi: 10.1007/s10584-009-9666-3

Montagne, D., Cousin, I., and Cornu, S. (2016). Changes in the pathway and the intensity of albic material genesis: role of agricultural practices. Geoderma 268, 156-164. doi: 10.1016/j.geoderma.2016.01.019

Montagne, D., Cousin, I., Josiere, O., and Cornu, S. (2013). Agricultural drainageinduced Albeluvisol evolution: a source of deterministic chaos. Geoderma 193, 109-116. doi: 10.1016/j.geoderma.2012.10.019
Rossiter, D., Hewitt, A. E., and Dominati, E. J. (2018). "Pedometric valuation of the soil resource," in Pedometrics, eds A.B. McBratney, B. Minasny, and U. Stockmann (Cham: Springer International Publishing AG), 521-546.

Schelling, J. (1970). Soil genesis, soil classification and soil survey. Geoderma 4, 165-193. doi: 10.1016/0016-7061(70)90002-9

Sergeev, A. O., Buevich, A. G., Baglaeva, E. M., and Shichkin, A. V. (2019). Combining spatial autocorrelation with machine learning increases prediction accuracy of soil heavy metals. Catena 174, 425-435. doi: 10.1016/j.catena.2018.11.037

Tarquis, A. M., Torre, E. G., Martin-Sotoca, J. J., Losada, J. C., Grau, J. B., Bird, N. R. A., et al. (2018). "Scaling characteristics of soil structure,"in Pedometrics, eds A. B. McBratney, B. Minasny, and U. Stockmann (Cham: Springer International Publishing AG), 155-193.

van Oort, F., Thiry, M., Foy, E., Fujisaki, K., Delarue, G., Dairon, R., et al. (2017) Impacts of one century of wastewater discharge on soil transformation through ferrolysis and related metal pollutant distributions. Sci. Total Environ. 590, 1-13. doi: 10.1016/j.scitotenv.2017.03.054

Vanwalleghem, T., Tarquis, A. M., and Minasny, B. (2018). Advances in pedometrics: special issue of Pedometrics 2015, Cordoba. Geoderma 311, 91-92. doi: 10.1016/j.geoderma.2017.05.042

Webster, R. (1994). The development of pedometrics. Geoderma 62, 1-15. doi: 10.1016/0016-7061(94)90024-8

Conflict of Interest Statement: The author declares that the research was conducted in the absence of any commercial or financial relationships that could be construed as a potential conflict of interest.

Copyright (c) 2019 Baveye. This is an open-access article distributed under the terms of the Creative Commons Attribution License (CC BY). The use, distribution or reproduction in other forums is permitted, provided the original author(s) and the copyright owner(s) are credited and that the original publication in this journal is cited, in accordance with accepted academic practice. No use, distribution or reproduction is permitted which does not comply with these terms. 